\title{
Speciation and selection without sex
}

\author{
C. William Birky Jr. ${ }^{1, *}$, Cynthia Wolf ${ }^{2,3}$, Heather Maughan ${ }^{4,5}$, Linnea Herbertson ${ }^{6,7}$ \\ Elena Henry ${ }^{8,9}$ \\ ${ }^{1}$ Department of Ecology and Evolutionary Biology and Graduate Interdisciplinary Program in Genetics, The University \\ of Arizona, Biological Sciences West, Tucson, AZ, 85745 USA \\ ${ }^{2}$ Department of Molecular and Cellular Biology, The University of Arizona, Biological Sciences West, Tucson, AZ, 85745 USA \\ ${ }^{3}$ Present address: Program in Genetic Counseling, The University of Texas Graduate School of Biomedical Sciences, \\ Houston, TX, 77225 USA \\ ${ }^{4}$ Graduate Interdisciplinary Program in Genetics, The University of Arizona, Biological Sciences West, Tucson, AZ, 85745 USA \\ ${ }^{5}$ Present address: Department of Ecology and Evolutionary Biology, The University of Arizona, Biological Sciences West, \\ Tucson, AZ, 85745 \\ ${ }^{6}$ Department of Ecology and Evolutionary Biology, The University of Arizona, Biological Sciences West, Tucson, AZ 85745 \\ ${ }^{7}$ Present address: Aqauria, Inc., 6100 Condor Drive, Moorpark, CA, 93021 \\ ${ }^{8}$ Department of Molecular and Cellular Biology, The University of Arizona, Biological Sciences West, Tucson, AZ85745 \\ ${ }^{9} 4645$ Pueblo Ave., Sierra Vista, AZ 85650 USA \\ (*Author for correspondence: E-mail: birky@u.arizona.edu)
}

Key words: cladogenesis, speciation, asexual reproduction, bdelloid rotifer, natural selection

\begin{abstract}
More than 100 females of the obligately asexual bdelloid rotifers were isolated from nature and their mitochondrial $\operatorname{cox} 1$ genes (encoding cytochrome oxidase subunit 1) were sequenced. Phylogenetic analysis of the sequences showed that most of the isolates fall into 21 clades that show two characteristics of species: they are reciprocally monophyletic and have sequence diversities similar to that of species in other organisms. These clades have been evolving independently in spite of being effectively sympatric, indicating that they are adapted to different ecological niches. In support of this, at least some of the clades differ in morphology, food utilization, and temperature tolerance. We conclude that the bdelloid rotifers have undergone substantial speciation in the absence of sexual reproduction. We also used these sequences to test the prediction that asexual organisms should be subject to relaxed natural selection and hence will accumulate detrimental mutations. In contrast to this prediction, several estimates of the ratio $K_{\mathrm{a}} / K_{\mathrm{s}}$ for the coxl gene showed that this gene is subject to strong selection in the bdelloid rotifers.
\end{abstract}

\section{Introduction}

"Sex is the queen of problems in evolutionary biology. Perhaps no other natural phenomenon has aroused so much interest; certainly none has sowed as much confusion." Graham Bell 1982 The Masterpiece of Nature

"These facts ... seemed to throw some light on the origin of species - that mystery of mysteries, as it has been called by one of our greatest philosophers." Charles Darwin 1859 The Origin of Species (p. 11 in The Modern Library edition).
The phylum Rotifera includes groups in which sexual reproduction is obligatory, interspersed with asexual reproduction, or lacking entirely and replaced by obligate asexual reproduction. Rotifers are thus ideal for studying two of the most important questions in biology: What is the evolutionary advantage of sexual reproduction? and What are species and how do they arise?

The evolutionary advantage of sex can be illustrated with the monogonont rotifers. Monogononts can lose facultative sexual reproduction as a consequence of a single mutation in any one of the 
genes required for sex. The loss quickly becomes irreversible as additional mutations accumulate in these genes. Moreover, asexual mutants have as much as a two-fold advantage and so should be quickly fixed in the population and species. This begs the question, why haven't all the sexual monogononts been replaced by obligately asexual lineages? Evidently sexual organisms enjoy compensating advantages which give them a higher speciation rate or lower extinction rate than asexual organisms. There are many theories about the selective advantages that favor sexual organisms and species over asexuals (Bell, 1982; Kondrashov, 1993; Barton \& Charlesworth, 1998). Most of these can be summarized in one general statement: natural selection works better with sex. Asexual clones and species should accumulate more detrimental mutations than sexual lineages and species (Muller's ratchet). The increased genetic load should lead to extinction of the mutant clone or species (the meltdown). Moreover, asexual clones and species will be less able to fix advantageous mutations and adapt to different habitats. To the extent that speciation depends on adaptation to different niches, asexual species will be less able to speciate. If asexual lineages have a high rate of extinction and a low rate of speciation, then the net rate of speciation (speciation minus extinction) will be low in asexual organisms. Clearly, the question of the evolutionary advantage of sex and the question of the nature of species and speciation come to a common focus in asexual organisms.

In fact, the very possibility of speciation in asexuals is controversial for several reasons. One is the focus on the biological species concept, in which species boundaries are defined by the absence of sexual reproduction. As a result of this focus, most studies of speciation have dealt with the establishment of reproductive isolation in sexual organisms. The existence of species in asexual organisms is also controversial because of a misunderstanding of basic population genetics, leading to the misconception that the descendants of an asexual organism must form a continuum of genetic variation, or that sexual reproduction is necessary to hold a species together.

These misconceptions have been addressed theoretically by Barraclough et al. (2003). They used well-established results from coalescent theory to show that an asexual lineage can split into two or more independently evolving clades as a result of divergent selection for adaptation to different niches, geographic isolation, or both. This is illustrated in Figure 1. A common model of asexual reproduction is shown in Figure 1a in which an asexual organism divides repeatedly to produce a clone. If mutations occur randomly in the population, then individuals that separated in the sixth cell cycle will be very similar, while those that separated in the fifth cycle will have on average more mutational differences, and so on. The result is a continuum of genetic differences between individuals, with no gaps separating clades or species. However, this model assumes completely synchronous reproduction with all individuals having exactly the same number of offspring. In real life, reproduction is not synchronous; some individuals die without reproducing, while others leave variable numbers of offspring (Fig. 1b). At the level of the gene, this is random genetic drift. Clusters of similar organisms are produced but these clusters are transient and would not be considered different species. Divergent selection due to adaptation to different ecological niches (Fig. 1c) produces long-lasting clades that evolve independently of each other. These are likely to differ in morphology, physiology, or behavior, and would reasonably be called species.

Although it is clear that asexual organisms can speciate in theory at least, theory does not make a clear prediction about whether the rate of speciation will be less than it is in similar sexual organisms. As discussed above, natural selection is predicted to be less effective in asexual organisms, making it more difficult to fix the mutations required for adaptation to different niches. Also asexuals cannot speciate in allopatry without adapting to different niches, while sexual organisms can, at least in principle. On the other hand, asexuals do not have to evolve reproductive isolation in order to speciate, since they are already reproductively isolated from each other. Asexuals are generally more effective colonizers than sexuals and hence are more likely to be exposed to different selective pressures. Finally, genetic hitchhiking in asexuals facilitates cladogenesis during divergent selection. Barraclough et al. (2003) concluded that the extent to which asexual organisms speciate is an empirical question. We undertook to determine whether the obligately asexual bdelloid rotifers have undergone speciation. 
(a)

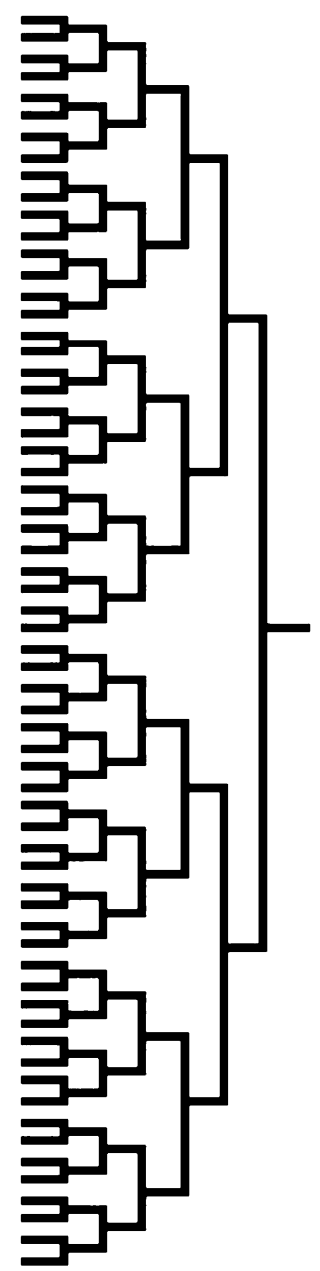

(b)

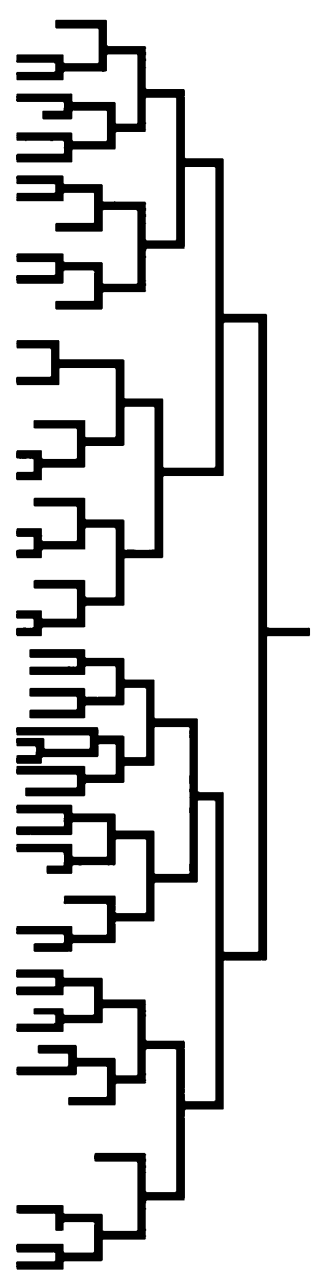

(c)

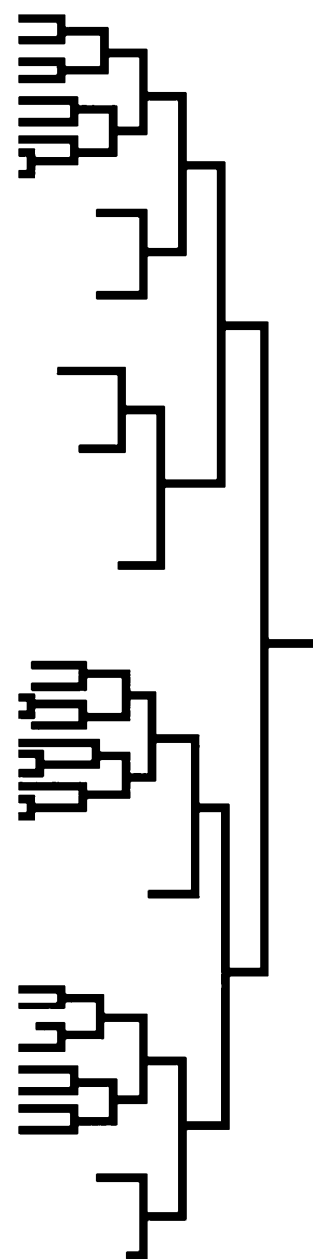

Figure 1. Diagrams illustrating asexual reproduction that is (a) synchronous with all individuals having the same number of offspring; (b) asynchronous with variable numbers of offspring and extinction (zero offspring), i.e. random drift at the gene level; and (c) drift plus divergent selection for adaptation to three different ecological niches.

Although the bdelloids have been divided into 4 families, 18 genera, and more than 374 species (Donner, 1965; Segers, 2002), this has been done largely on morphological grounds. While the species so described are as stable as species in the facultatively sexual monogononts (Holman, 1987), we believe that the definition and identification of species needs to be corroborated by phylogenetic analyses of DNA sequence data. Papers in this symposium and elsewhere show that traditional taxonomy of the monogononts does not always agree with molecular phylogenies. In particular, the identification of sibling or cryptic species seems to be common in rotifers as it is with many other invertebrates and protists (Derry et al., 2003; Gómez, 2004, Part II. Genetics and Molecular Ecology). We sequenced the mitochondrial coxl gene from a large collection of individual bdelloids isolated from nature. Phylogenetic analysis of these sequences revealed 21 independently evolving clades with diversity similar to that found in species of sexual organisms. Identification of these clades as species was supported by evidence for adaptive differences between some of the clades in morphology, food utilization, and temperature 
tolerance. Our results provide the first molecular phylogenetic evidence for substantial speciation in an asexual lineage.

The same sequence data used for phylogenetic analysis can also be used to test theories about the evolutionary advantage of sex. In particular, it can be used to test the prediction that asexual lineages should accumulate detrimental mutations to a greater extent than do sexual lineages. This phenomenon, called Muller's ratchet, is a special case of the Hill-Robertson effect (Barton \& Charlesworth, 1998), in which selection acting on one site interferes with selection acting on all linked sites. Although the Hill-Robertson effect is based on robust theory and is almost certainly applicable to all asexual organisms, the strength of its effect depends on a number of factors, notably selection intensity and population size. Consequently, the accumulation of detrimental mutations (and likewise the reduction in speciation) may not be significant. The extent to which detrimental mutations are fixed in a lineage can be estimated by $K_{\mathrm{a}} / K_{\mathrm{s}}$, the ratio of amino acid substitutions (mostly detrimental or neutral) to synonymous substitutions (mostly neutral) along the lineage. Using this measure, we were unable to detect any greater accumulation of detrimental mutations in the bdelloids than in the monogononts or other sexual organisms. Thus, it seems unlikely that bdelloid species have an unusually high rate of extinction due to genetic load.

\section{Materials and methods}

We collected 102 individual female bdelloids from nature; 8 more were obtained from other laboratories or commercial sources. They were reared in the lab on algae (Chlamydomonas reinhardtii or Chlorella vulgaris) or bacteria (Escherichia coli or Klebsiella pneumoniae pneumoniae), or a combination of these, to produce clones of females. All were identified to genus and some to species. The descendants of a single bdelloid constitute a clone. Table 1 gives the classification and origin of each clone and the accession number of the corresponding coxl sequence.

Approximately 100 females from each clone were washed free of food organisms by exposure to dilute detergent (SDS), rinsed in sterile distilled water, starved for 5-7 days to eliminate food from their digestive tract, and washed again. Adineta and Habrotrocha were simply rinsed repeatedly in sterile distilled water before and after starvation, because they are sensitive to SDS. After the final wash or rinse, animals were collected in a minimal volume of distilled water in a microfuge tube and stored at $-20{ }^{\circ} \mathrm{C}$.

QIAmp or DNeasy spin columns (QiaGen) were used to isolate DNA from frozen rotifers. In a few cases, rotifers were lysed with SDS and proteinase $\mathrm{K}$, then DNA was purified by a phenol-chloroform-isoamyl alcohol procedure. The mitochondrial coxl gene encoding cytochrome oxidase subunit 1 was amplified from the DNA by the PCR using primers $\mathrm{HCO} 5^{\prime}$ TAAACTTCAGGGTGACCAAAAAATCA, and LCO 5' GGTCAACAAATCATAAAGATATTG $\mathrm{G}$ (Hoeh et al., 1998). The amplification product was purified with QIAquick columns (QiaGen) and sequenced in both directions by the Genomic Analysis and Technology Core at the University of Arizona using the amplification primers. From each clone, we obtained 591 bases of unambiguous sequence for cox 1 , corresponding to sites 77-666 of the human sequence, with the insertion of one codon in the bdelloid sequence.

The coxl sequences of monogonont rotifers used as the outgroup were taken from GenBank; accession numbers are in Table 1. Each Brachionus plicatilis sequence was obtained from a single fertilized egg (Gómez et al., 2000) which would have hatched to produce a clone of asexual monogonont females. Sequences from B. quadridentatus, B. calyciflorus 6ALM, and Hexarthra sp. 1ERA were provided by Africa Gómez and are unpublished. We will refer to each of the monogonont sequences as a clone.

Initially, cox 1 sequences were aligned with Clustal W implemented in the SeqApp or SeqPup programs (Gilbert, 1992) and the alignment was verified by examining the inferred amino acid sequences. Thereafter, additional bdelloid sequences could be unambiguously aligned by eye. There were some gaps and differences in sequence length; we used only regions present in all sequences. Phylogenetic trees were made in PAUP* (Swofford, 1998) using parsimony or neighbor-joining. The latter used pairwise sequence differences corrected for multiple hits 
Table 1. List of clones used in this study, with their origins and identification, and GenBank accession numbers of their cox 1 sequences. Bdelloid clones collected by the authors are identified by 3- to 5-letter names indicating the location, followed by collection number/clone number. Exact locations of collecting sites are available from the author.

\begin{tabular}{|c|c|c|c|}
\hline Species & Clone & Origin & GenBank \\
\hline Adineta vaga & WAv1/1 & Italy $^{\mathrm{a}}$ & DQ078512 \\
\hline Adineta sp. & Roul/6 & Round Valley, Chniricahua Mts, AZ & DQ078513 \\
\hline Adineta oculata & Warl/1 & unknown $^{\mathrm{b}}$ & DQ078515 \\
\hline Adineta sp. & Rou $1 / 8$ & Round Valley, Chniricahua Mts, AZ & DQ078514 \\
\hline Habrotrocha sp. & HuH1-4a & Arizona & DQ078516 \\
\hline Habrotrocha sp. & Rob2/10d & Arizona & DQ078517 \\
\hline Habrotrocha sp. & $\operatorname{Bir} 2 / 3$ & Tucson, AZ & DQ078518 \\
\hline Adineta sp. & $\mathrm{BCB} 1 / 2 \mathrm{~b}$ & Arizona & DQ078519 \\
\hline Habrotrocha constricta & WHcl/1 & Sandwich, $\mathrm{MA}^{\mathrm{c}}$ & DQ078520 \\
\hline Habrotrocha sp. & Smok1/1 & Great Smoky Mountain NP, TN & DQ078521 \\
\hline Habrotrocha sp. & Smok $1 / 2$ & Great Smoky Mountain NP, TN & DQ078522 \\
\hline Habrotrocha sp. & $\operatorname{Pim} 1 / 1$ & Pima Canyon, Santa Catalina Mts, AZ & DQ078523 \\
\hline Habrotrocha sp. & Glen $1 / 10$ & Glenwood, NM & DQ078524 \\
\hline Habrotrocha sp. & Glen $1 / 5$ & Glenwood, NM & DQ078525 \\
\hline Habrotrocha sp. & Rob2/8 & Robinsom Spring, Santa Rita Mts, AZ & DQ078526 \\
\hline Habrotrocha sp. & Rob2/7 & Robinsom Spring, Santa Rita Mts, AZ & DQ078527 \\
\hline Habrotrocha sp. & Rob2/9 & Robinsom Spring, Santa Rita Mts, AZ & DQ078528 \\
\hline Habrotrocha sp. & $\mathrm{HuH} 1 / 5 b$ & Hex pool, Hueco Tanks State Park, TX & DQ078529 \\
\hline Habrotrocha sp. & Rob2/10a & Arizona & DQ078530 \\
\hline Habrotrocha sp. & $\mathrm{HuH} 1 / 5 \mathrm{a}$ & Hex pool, Hueco Tanks State Park, TX & DQ078531 \\
\hline Habrotrocha sp. & Rob2/10c & Arizona & DQ078532 \\
\hline Habrotrocha sp. & Wad1/7 & Tucson, AZ & DQ078533 \\
\hline Habrotrocha sp. & Wad1/9 & Tucson, AZ & DQ078534 \\
\hline Abrochtha sp. & Angl1/1 & Angelfish pool, Virginia Dale, CO & DQ078535 \\
\hline Macrotrachela quadricornifera & WMq & Italy $^{a}$ & DQ078536 \\
\hline Macrotrachela sp. & Trap $1 / 2$ & Trap Lake, Front Range, CO & DQ078537 \\
\hline Macrotrachela sp. & $\mathrm{HuH} 1 / 1$ & Hex pool, Hueco Tanks State Park, TX & DQ078538 \\
\hline Macrotrachela sp. & HuJu1/10 & Julie?s pool, Hueco Tanks State Park, TX & DQ078540 \\
\hline Macrotrachela sp. & HuJu1/12 & Julie?s pool, Hueco Tanks State Park, TX & DQ078539 \\
\hline Macrotrachela sp. & SnoB1/3 & Snowy Range, WY & DQ078541 \\
\hline Macrotrachela sp. & SnoB $1 / 7$ & Snowy Range, WY & DQ078542 \\
\hline Rotaria sp. & Trap1/1 & Trap Lake, Front Range, CO & DQ078543 \\
\hline Philodina roseola & WPr1/1 & unknown $^{\mathrm{d}}$ & DQ078544 \\
\hline Philodina sp. & Car1/1 & unknown $^{\mathrm{e}}$ & DQ078545 \\
\hline Philodina sp. & $\mathrm{Car} / \operatorname{Pr} 2$ & unknown $^{\mathrm{e}}$ & DQ078546 \\
\hline Philodina sp. & Car/Pr1 & unknown $^{\mathrm{e}}$ & DQ078547 \\
\hline Philodina sp. & $\mathrm{HuJ} 1 / 1$ & Jenn?s pool, Hueco Tanks State Park, TX & DQ078548 \\
\hline Philodina sp. & Hufl/1 & Pool f, Hueco Tanks State Park, TX & DQ078549 \\
\hline Philodina sp. & Hufl $1 / 2$ & Pool f, Hueco Tanks State Park, TX & DQ078550 \\
\hline Philodina sp. & Huf $1 / 3$ & Pool f, Hueco Tanks State Park, TX & DQ078551 \\
\hline Philodina sp. & $\mathrm{FlT} 2 / 1$ & Florida Canyon, Santa Rita Mts, AZ & DQ078552 \\
\hline Philodina sp. & $\mathrm{HuN} 1 / 1$ & North pool, Huech Tanks State Park, TX & DQ078553 \\
\hline Philodina sp. & $\mathrm{HuN} 1 / 2$ & North pool, Huech Tanks State Park, TX & DQ078554 \\
\hline Philodina sp. & $\mathrm{ScM} 1 / 1$ & Scotia Canyon, Huachucha Mts, AZ & DQ078555 \\
\hline
\end{tabular}


Table 1. (Continued)

\begin{tabular}{|c|c|c|c|}
\hline Species & Clone & Origin & GenBank \\
\hline Philodina sp. & Duc1/1 & Sierra Vista, AZ & DQ078556 \\
\hline Philodina sp. & Duc1/2 & Sierra Vista, AZ & DQ078557 \\
\hline Philodina sp. & $\mathrm{PaP} 1 / 3$ & Paton's pond, Patagonia, AZ & DQ078558 \\
\hline Philodina sp. & FRP1/3 & Unnamed canyon, Santa Catalina Mts, AZ & DQ078559 \\
\hline Philodina sp. & $\mathrm{FlT} 2 / 2$ & Florida Canyon, Santa Rita Mts, AZ & DQ078560 \\
\hline Philodina sp. & $\mathrm{FlT} 2 / 3 \mathrm{c}$ & Florida Canyon, Santa Rita Mts, AZ & DQ078561 \\
\hline Philodina sp. & HuK $1 / 1$ & Kettle Pool, Hueco Tanks State Park, TX & DQ078562 \\
\hline Philodina sp. & $\mathrm{HuK} 1 / 2$ & Kettle Pool, Hueco Tanks State Park, TX & DQ078563 \\
\hline Philodina sp. & Chil/1 & Chino Canyon, Santa Rita Mts, AZ & DQ078564 \\
\hline Philodina sp. & Will/2 & Wilderness of Rocks, Santa Catalina Mts, AZ & DQ078565 \\
\hline Philodina sp. & Will/3 & Wilderness of Rocks, Santa Catalina Mts, AZ & DQ078566 \\
\hline Philodina sp. & SwT1/2 & Sweetwater Wetlands, Tucson, AZ & DQ078567 \\
\hline Philodina sp. & Yet1/1 & Yetman trail, Tucson Mts, AZ & DQ078568 \\
\hline Philodina sp. & Yet1/3 & Yetman trail, Tucson Mts, AZ & DQ078569 \\
\hline Philodina sp. & Yet2/1 & Yetman trail, Tucson Mts, AZ & DQ078570 \\
\hline Philodina sp. & Yet $2 / 2$ & Yetman trail, Tucson Mts, AZ & DQ078571 \\
\hline Philodina sp. & Yet $2 / 4$ & Yetman trail, Tucson Mts, AZ & DQ078572 \\
\hline Philodina sp. & Yet2/6 & Yetman trail, Tucson Mts, AZ & DQ078573 \\
\hline Philodina sp. & Yet2/7 & Yetman trail, Tucson Mts, AZ & DQ078574 \\
\hline Philodina sp. & Yet2/8 & Yetman trail, Tucson Mts, AZ & DQ078575 \\
\hline Philodina sp. & Yet2/9 & Yetman trail, Tucson Mts, AZ & DQ078576 \\
\hline Philodina sp. & Yet2/10 & Yetman trail, Tucson Mts, AZ & DQ078577 \\
\hline Philodina sp. & Ven $1 / 3$ & Ventana Canyon, Santa Catalina Mts, AZ & DQ078578 \\
\hline Philodina sp. & Yet $1 / 2$ & Yetman trail, Tucson Mts, AZ & DQ078579 \\
\hline Philodina sp. & Amp $1 / 1$ & Pontatoc Canyon, Santa Catalina Mts, AZ & DQ078580 \\
\hline Philodina sp. & Amp $1 / 2$ & Pontatoc Canyon, Santa Catalina Mts, AZ & DQ078581 \\
\hline Philodina sp. & Amp $1 / 3$ & Pontatoc Canyon, Santa Catalina Mts, AZ & DQ078582 \\
\hline Philodina sp. & Ven $1 / 2$ & Ventana Canyon, Santa Catalina Mts, AZ & DQ078583 \\
\hline Philodina sp. & Kof $1 / 4$ & Palm Canyon, Kofa NWR, AZ & DQ078584 \\
\hline Philodina sp. & Kof $1 / 5$ & Palm Canyon, Kofa NWR, AZ & DQ078585 \\
\hline Philodina sp. & Kof $1 / 2$ & Palm Canyon, Kofa NWR, AZ & DQ078587 \\
\hline Philodina sp. & Kof $1 / 1$ & Palm Canyon, Kofa NWR, AZ & DQ078586 \\
\hline Philodina sp. & Kof $1 / 3$ & Palm Canyon, Kofa NWR, AZ & DQ078588 \\
\hline Philodina sp. & Kof $1 / 6$ & Palm Canyon, Kofa NWR, AZ & DQ078589 \\
\hline Philodina sp. & Hel1/3 & Helvetia, Santa Rita Mts, AZ & DQ078590 \\
\hline Philodina sp. & Yet $2 / 5$ & Yetman trail, Tucson Mts, AZ & DQ078591 \\
\hline Philodina sp. & $\operatorname{Bird} 2 / 2$ & Tucson, AZ & DQ078592 \\
\hline Philodina sp. & BirdE1/1 & Tucson, AZ & DQ078593 \\
\hline Philodina sp. & BirdT1/3 & Tucson, AZ & DQ078594 \\
\hline Philodina sp. & Yet $2 / 3$ & Yetman trail, Tucson Mts, AZ & DQ078595 \\
\hline Philodina sp. & $\operatorname{Bir} 1 / 1$ & Tucson, AZ & DQ078596 \\
\hline Philodina sp. & Gut1blb & Columbus, $\mathrm{OH}$ & DQ078597 \\
\hline Philodina sp. & Gut1/1c & Columbus, $\mathrm{OH}$ & DQ078598 \\
\hline Philodina sp. & Roul/3 & Round Valley, Chniricahua Mts, AZ & DQ078599 \\
\hline Philodina sp. & Hell $/ 2$ & Helvetia, Santa Rita Mts, AZ & DQ078600 \\
\hline Philodina sp. & Rou $1 / 10$ & Round Valley, Chniricahua Mts, AZ & DQ078601 \\
\hline
\end{tabular}


Table 1. (Continued)

\begin{tabular}{|c|c|c|c|}
\hline Species & Clone & Origin & GenBank \\
\hline Philodina sp. & Bel1/1 & Bellows Spring, Santa Rita Mts, AZ & DQ078606 \\
\hline Philodina sp. & Bel1/2 & Bellows Spring, Santa Rita Mts, AZ & DQ078602 \\
\hline Philodina sp. & Bell $/ 4$ & Bellows Spring, Santa Rita Mts, AZ & DQ078607 \\
\hline Philodina sp. & Bel1/5 & Bellows Spring, Santa Rita Mts, AZ & DQ078603 \\
\hline Philodina sp. & Bell/8 & Bellows Spring, Santa Rita Mts, AZ & DQ078604 \\
\hline Philodina sp. & Bell/10 & Bellows Spring, Santa Rita Mts, AZ & DQ078605 \\
\hline Philodina sp. & Bel2/1 & Bellows Spring, Santa Rita Mts, AZ & DQ078609 \\
\hline Philodina sp. & Bel2/5 & Bellows Spring, Santa Rita Mts, AZ & DQ078610 \\
\hline Philodina sp. & $\operatorname{Bel} 2 / 6$ & Bellows Spring, Santa Rita Mts, AZ & DQ078611 \\
\hline Philodina sp. & Bel2/8 & Bellows Spring, Santa Rita Mts, AZ & DQ078608 \\
\hline Philodina sp. & Fin $1 / 1$ & Finger Rock Canyon, Santa Catalina Mts, AZ & DQ078612 \\
\hline Philodina sp. & Rou1/2 & Round Valley, Chniricahua Mts, AZ & DQ078613 \\
\hline Philodina sp. & Roul/4 & Round Valley, Chniricahua Mts, AZ & DQ078614 \\
\hline Philodina sp. & Rat1/1 & Rat Cave pool, Virginia Dale, CO & DQ078615 \\
\hline Philodina sp. & Rat1/2 & Rat Cave pool, Virginia Dale, CO & DQ078616 \\
\hline Philodina sp. & Rat1/3 & Rat Cave pool, Virginia Dale, CO & DQ078617 \\
\hline Philodina sp. & Angl1/3 & Angelfish pool, Virginia Dale, CO & DQ078618 \\
\hline Philodina sp. & Bearl/2 & Bear Canyon, Santa Catalina Mts, AZ & DQ078619 \\
\hline Philodina sp. & Bearl/1 & Bear Canyon, Santa Catalina Mts, AZ & DQ078620 \\
\hline Philodina sp. & FIT3 $/ 3$ & Florida Canyon, Santa Rita Mts, AZ & DQ078621 \\
\hline Brachionus plicatilis & B.plicat(6TUR1) & Spain ${ }^{\mathrm{f}}$ & AF266859 \\
\hline Brachionus plicatilis & B.plicat(2SA21) & Spain ${ }^{f}$ & AF266896 \\
\hline Brachionus quadridentatus & B.quadrid & Spain ${ }^{\mathrm{g}}$ & \\
\hline Brachionus calyciflorus & B.calycif & Spain ${ }^{g}$ & \\
\hline Hexarthra sp. & Hexarthra_sp. & Spain ${ }^{\mathrm{g}}$ & \\
\hline
\end{tabular}

${ }^{\mathrm{a}}$ From Claudia Ricci and Giulio Melone via David Mark Welch. ${ }^{\mathrm{b}}$ Purchased from Ward? Natural Science Establishment, Inc. ${ }^{\mathrm{c}}$ From David Mark Welch. ${ }^{\mathrm{d}}$ From Carolina Biological Supply Company via David Mark Welch. ${ }^{\mathrm{e}}$ Purchased from Carolina Biological Supply Company. ${ }^{\mathrm{f}}$ (Gómez et al. 2000). ${ }^{\mathrm{g}}$ Sequences provided by Africa Gómez.

with the GTR + I + G model and parameters selected with the maximum likelihood algorithm in ModelTest (Posada \& Crandall, 1998).

For testing food utilization, each clone was reared for $\geq 7$ days in parallel cultures on each of the experimental food sources (E. coli or C. reinhardtii). Then the growth of each clone on each food was assayed by isolating 10 randomly chosen females in each of 10 depression slides in approximately $1 \mathrm{ml}$ of distilled water at $25^{\circ} \mathrm{C}$. Excess food organisms (E. coli or $C$. reinhardtii) were added. After approximately $2,4,6$, and 8 days, the fluid was replaced with fresh water and food organisms and animals were counted. After an initial lag, the number of animals increased logarithmically. Log growth rates were compared using ANOVA.

The temperature tolerance of a clone was measured by isolating 12 females aged $<24 \mathrm{~h}$ in depression slides with excess $C$. reinhardtii at each temperature $\left(16,27,36^{\circ} \mathrm{C}\right)$. Animals were counted and the fluid was replaced with fresh food and water at intervals that varied with the growth rate of the cultures. After an initial lag, the number of animals increased logarithmically. Log growth rates were compared using ANOVA.

\section{Results}

\section{Cladogenesis in bdelloid rotifers}

Bdelloids were collected from sites in Arizona, Massachusetts, New Mexico, Colorado, Illinois, Ohio, and Tennessee in the U.S. and from Italy (Table 1). Collection sites included temporary and permanent lakes, ponds, streams, and springs, dirt, 
and moss, at elevations ranging from sea level to $3660 \mathrm{~m}$. In the laboratory, individual females were isolated, a clone was reared from each female, and the coxl gene was sequenced from each clone. Phylogenetic trees were made from these sequences plus those of four monogonont rotifers as an outgroup. Details of this analysis, and its application to a larger dataset, will be presented elsewhere; here we give only a brief summary.

Trees made with either parsimony or neighborjoining showed the striking pattern illustrated in Figure 2, in which 21 shallow clades with $\geq 70 \%$ bootstrap support are separated from each other and from the remaining clones by deep branches. The deep branches are joined at a polytomy, which can be partially resolved with the aid of additional sequence data from the mitochondrial cob gene (not shown). There are very few intermediate branches.

The well-supported shallow clades meet two criteria for potential species:

1. The within-clade nucleotide diversity is $\leq 2 \%$, similar to that of well-established species in many other organisms (e.g., Avise, 1994; Moriyama \& Powell, 1996).

2. The sequence differences between the clades are at least four times greater than the maximum diversity within the clades. This makes it likely that the clades represent samples from populations that are reciprocally monophyletic, based on the following reasoning: The neutral expectation of the pairwise differences within a population (nucleotide diversity $\pi$ ) is approximately $2 \mathrm{~N}_{\mathrm{e}} \mathrm{u}$ for mitochondrial genes (Birky et al., 1983), or less due to hitchhiking (Maruyama \& Birky, 1991). Also it takes $4 \mathrm{~N}_{\mathrm{e}}$ generations for $95 \%$ of pairs of sister species to become reciprocally monophyletic in an asexual genome (Avise \& Ball, 1990; Avise, 1994), at which point the mean pairwise difference between the species is $d=8 \mathrm{~N}_{\mathrm{e}} \mathrm{u}$. Moreover, Rosenberg (2003) showed that when $d \geq 4 \mathrm{~N}_{\mathrm{e}} \mathrm{u}$, one can infer reciprocal monophyly of the populations from which the clades are samples with $95 \%$ probability. This theory was developed for uniparentally inherited mitochondrial or chloroplast genes. Although it would not apply to nuclear genes in a sexual organism
(Hudson \& Coyne, 2002), it does apply to all genes in the asexual bdelloids because all nuclear and organelle genes behave as a single non-recombining unit

\section{Niche adaptation in bdelloid clades}

Two or more clades will be reciprocally monophyletic if the populations of bdelloids that they represent have been evolving independently of each other for a long time. Two or more lineages are most likely to evolve independently if they are permanently geographically isolated or if they are adapted to different niches.

Several lines of evidence make it very unlikely that our clades have been geographically isolated during their evolution. The evidence is described in detail elsewhere and will only be summarized here.

1. In several cases, members of different clades or singlets were isolated from the same sample. These cases are:

Abr1, Pha10 from temporary pool, Virginia

Dale, CO (sample Angl1)

Adi singlet Bird2/3, Pha singlet Bird2/4, Pha6, from bird bath, Tucson, AZ (Bird2)

Pha6, Pha8, from temporary stream, Helvetia, AZ (Hel1)

Adi1, Pha8, Pha10, from temporary stream, Round Valley, AZ (Rou1)

Pha5a, Pha5b, from temporary pool, Kofa National Wildlife Refuge, AZ (Kofa1)

Pha4, Pha6, Pha7, from dust, Yetman trail, Tucson, AZ (Yet2)

2. Bdelloids survive dessication and disperse in the wind, and colonize habitats quickly and effectively (Cáceres \& Soluk, 2002).

3. We were able to estimate the dispersal rate of animals in clade Pha8. The clones in this clade were collected in Columbus, Ohio and from Helvetia and Round Valley in Arizona. We divided the geographic distance between each site in Arizona and Ohio by the sequence difference between each pair of Arizona and Ohio rotifers to obtain a dispersal rate of $613 \mathrm{~km} / \%$ sequence difference. These clones are separated from clones in other clades and from singlets by a median sequence difference of about $50 \%$, so they could have dispersed by 


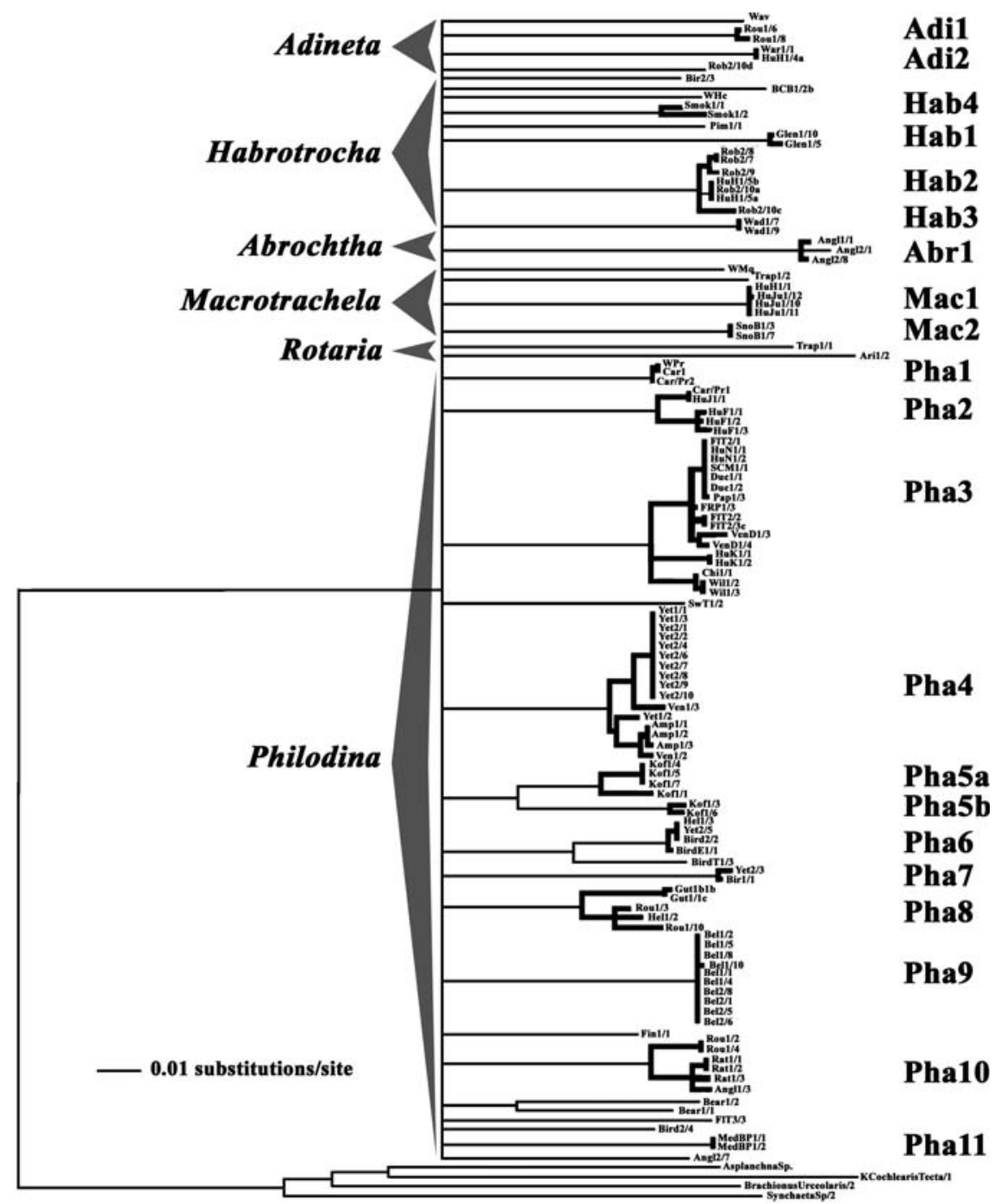

Figure 2. Bootstrapped neighbor-joining tree using pairwise distances corrected for multiple hits with the general time reversible plus invariant sites and gamma-distributed variable sites. Clades that are putative species are shown with bold lines and named on the right (e.g., Adil for Adineta clade 1, Pha6 for Philodina clade 6, etc. Genera are indicated left of the basal polytomy.

over $613 \times 50=30,646 \mathrm{~km}$ since they diverged from the other clades. This is about $3 / 4$ of the circumference of the earth.

We plotted the geographic distance versus the sequence difference between each pair of clades, using amino acid sequences to avoid possible problems with saturation. The Mantel test, implemented in IBD (Bohonak, 2002), showed a significant correlation between geographic distance and sequence difference but the regression line has a very small slope, indicating rapid dispersal. Using the rate of dispersal estimated by this slope, we found that the bdelloid clades could have dispersed around the world many times since their divergence.

It thus appears that most or all of our clades have repeatedly colonized the same bodies of water. Their continued independent evolution can then be most easily explained if they are adapted to different niches. We obtained direct evidence that at least some of our clades are adapted to different niches.

First, at least some of the clades utilize different, albeit overlapping, food sources. We identified all clones to genus based on discrete morphological differences, and some of these differences 
almost certainly result from adaptation to different feeding methods. For example, Adineta lack a ciliated corona and cannot swim or feed on suspended particles; instead they glide over the substrate and presumably scrape up food with the comb-like structure just behind the ventral mouth. In contrast, Philodina, Macrotrachela, and Rotaria have ciliated coronas which they can use while swimming or to create a vortex that brings food to their mouths while they are attached to the substrate. Besides feeding on suspended material, they can also pick up food from the substrate in their immediate perimeter while attached by the toes.

We hypothesized that Philodina and Adineta are adapted to feed on suspended organisms or organisms on the substrate, respectively. In preliminary experiments to test this, we compared the food utilization of a clone of Adineta, Bird2/3, and one of Philodina, FlT2/1. The population growth of these clones was compared on two different food sources, the motile green alga $C$. reinhardtii and the nonmotile bacterium $K$. pneumoniae pneumoniae. For each clone and each food source, 10 replicate cultures were initiated with 1 randomly chosen female in distilled water with excess food and counted every one to two days. Population growth became loglinear after an initial lag; the slope of the loglinear phase is an estimate of the intrinsic rate of natural increase $r$. The results (Table 2) show a significant difference $(p<0.001)$ in food utilization between these two clones. The difference might be related to swimming versus nonmotile food as hypothesized. However, because Klebsiella is much smaller than Chlamydomonas, there could also be a preference for particle size (Vadstein et al., 1993; Ronneberger, 1998), or there might be a difference in nutritional quality. More extensive experiments by Ricci $(1984,1991)$ demonstrated differences in food utilization

Table 2. Log growth rates (in females $\times$ day $^{-1} \times$ female $^{-1}$ ) of Adineta and Philodina fed bacteria and algae

\begin{tabular}{lll}
\hline Bdelloid clone (clade) & Bacteria & Algae \\
\hline Adineta $($ Bird2/3) & 0.0138 & 0.0102 \\
Philodina $($ FlT2/1) & 0.0113 & 0.0173 \\
\hline
\end{tabular}

Differences between food sources within clones and between clones are statistically significant $(p<0.001)$. between genus and also between species of the same genus and between isolates of one species.

Another likely kind of adaptation in bdelloids is to temperature. We compared the temperature tolerances of clones from two Philodina clades, Pha2 and Pha3. From each clone, 12 replicate cultures were initiated with 1 immature female at 16,27 , and $36^{\circ} \mathrm{C}$ with Chlamydomonas as food. Each of these is referred to as a line. Animals were counted daily and the number of animals plotted against time, with the following results:

1. At $36{ }^{\circ} \mathrm{C}$, only lines from clade Pha2 (clones Huf $1 / 1$, Huf1/2, and Huf1/3) survived. The rate of reproduction varied greatly among the 12 lines of each clone; some never achieved log growth; and the number of animals increased erratically in some. The percentage of females that survived and reproduced was $92 \%$ for Huf1/1, 67\% for Huf1/2, and 50\% for Huf1/3. All of the females from clade Pha3 (clones Duc1/2, FlT2/1, and HuN1/1) died without reproducing. Some of the death may have been due to damage during isolation, but this should affect all the clones about equally.

2. At $27^{\circ} \mathrm{C}$, clones from the two clades differed in the length of a lag period before achieving exponential growth of numbers and in $\log$ growth rate. Pha3 clones (Duc1/1, Duc1/2, FlT2/1, HuN1/1) consistently have a shorter lag (ca. $45 \mathrm{~h}$ versus $75 \mathrm{~h}$ ) and higher log growth rates than the clones from Pha2 (Huf1/ 1 , Huf1/3). Some females died without reproducing, possibly due to damage during isolation. These lines were not included in the analysis, reducing the sample size below 12 . In contrast to the situation at $36{ }^{\circ} \mathrm{C}$, the number of non-reproducing animals was not significantly different between the two clades.

3. At $16{ }^{\circ} \mathrm{C}$, clones from clade Pha2 (Huf1/1, Huf1/2, Huf1/3) again had a longer lag time of ca. 250-400 h compared to those from Pha3 (Duc1/1, Duc1/2, FlT2/1, HuN1/1, HuN1/2, ScM1/1; $\leq 110$ h), but had similar log growth rates. Some animals died without reproducing, reducing the sample size. The numbers of nonreproducing animals was not significantly different between the two clades.

4. Two clones from Pha2 (Huf1/1, Huf1/3) and three clones from Pha3 (Duc1/2, FlT2/1, 
$\mathrm{HuN} 1 / 1)$ were tested at all temperatures; Figure 3 compares their mean log growth rates. The growth rates of Pha 2 clones were lower at both 16 and $27^{\circ} \mathrm{C}$ but the $95 \%$ confidence intervals overlapped.

We conclude that clade Pha2 is adapted to a higher temperature range than is clade Pha3.

Because bdelloids disperse and colonize readily, a female isolated from a particular site may not be well adapted to it; it may belong to a clone that is a recent arrival rather than a long-term resident. Consequently, when animals from different clades are found in the same sample of water, this is not by itself definitive evidence that those clades are adapted to different niches. However, collectively the data strongly suggest that the bdelloid clades identified as putative species have occupied the same bodies of water repeatedly if not continuously, and geographic isolation cannot explain their independent evolutionary paths.

We conclude that these clades fit most or all of the species definitions that are applicable to asexual as well as sexual organisms. In particular, they fit the phylogenetic and genealogical definitions that focus on reciprocal monophyly. They satisfy the evolutionary definition, which requires that they be following independent evolutionary paths. Finally, they fit the cohesion definition, which explains independent evolution in terms of demographic non-interchangeability due to adap-

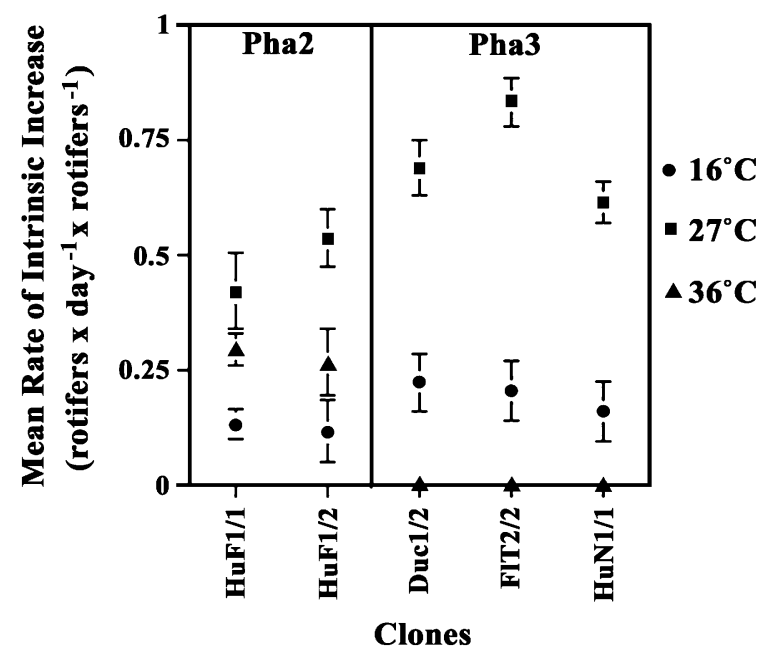

Figure 3. Means and 95\% confidence intervals of the log growth rates of all surviving lines from each of two clones of clade Pha2 and three clones of clade Pha3. tation to different niches. Contrary to some predictions, this ancient asexual lineage has undergone substantial speciation, driven at least in part by divergent selection.

Finally, we note that our results agree with the suggestion that coxl gene sequences could be used as a 'DNA barcode' to identify species (Hebert et al., 2003).

\section{Effectiveness of selection on a bdelloid mitochondrial gene}

The ability of bdelloids to speciate and survive for a very long time might indicate that natural selection continues to operate effectively on bdelloids in spite of their loss of sexual reproduction. We tested this possibility by estimating the proportion of mutations that change amino acids (nonsynonymous mutations) and are not eliminated by natural selection. This proportion is commonly estimated by $K_{\mathrm{a}} / K_{\mathrm{s}}$, the ratio of amino acid substitutions to synonymous substitutions. The rationale is that most synonymous mutations are neutral so $K_{\mathrm{s}}$ estimates the mutation rate. If selection is weaker in asexual than in sexual lineages due to the Hill-Robertson effect, a larger proportion of detrimental mutations will be fixed in the asexuals, and most of the detrimental mutations will be nonsynonymous.

Mitochondrial genes are inherited uniparentally, from the maternal parent only, in most animals (Birky, 1996). Therefore, it is likely that they are also inherited uniparentally in monogononts and in the common ancestor of monogononts and bdelloids. Nevertheless, the loss of sexual reproduction in bdelloids should result in a marked reduction in the effectiveness of selection for both mitochondrial and nuclear genes. The effectiveness of selection at any site in a genome is reduced by selection on other loci. This reduction is greatest when the other segregating loci are completely linked to the site (Hill \& Robertson, 1966). The larger the number of such linked loci, the greater is this Hill-Robertson effect (Birky \& Walsh, 1988). In sexual organisms, the nuclear and mitochondrial genomes are unlinked, and background selection on the nucleus has little effect on mitochondrial genes. In the bdelloids, loss of sex caused all the nuclear genes to become completely linked to each other and to the mitochondrial 
genes. Since nuclear genes outnumber mitochondrial genes by a factor of 500 or more, number of loci linked to a mitochondrial gene increases by the same factor with a resulting large increase in the Hill-Robertson effect.

We used two partial datasets to estimate $K_{\mathrm{a}} / K_{\mathrm{s}}$ in the mitochondrial coxl gene. The 'large' data set consisted of 51 bdelloids selected to include a single member of most clades and some singlets, 5 monogononts, and the cephalopod Gonatus onyx as an outgroup. Figure 4 is a bootstrapped parsimony tree to illustrate the cladistic relationships of the clones in the large dataset. The 'small' dataset included 22 bdelloids, 3 monogononts, and the cephalopod. This dataset was used because some analyses required too much computation time to be applied to the larger dataset. The phylogenetic tree in Figure 5 was used for the maximum likelihood analysis of the large dataset.

We first estimated $K_{\mathrm{a}} / K_{\mathrm{s}}$ for coxl among the clones in the large dataset. Maximum likelihood analysis of this dataset was not computationally feasible, so we used $K_{12} / K_{3}$ as an estimator of $K_{\mathrm{a}} /$ $K_{\mathrm{s}}$ (most substitutions in positions 1 and $2, K_{12}$, are nonsynonymous, while most substitutions in position $3, K_{3}$, are synonymous). We made neighbor-joining trees with the Jukes-Cantor model for the first and second codon positions, then separately for the third codon position. We then calculated $K_{12} / K_{3}$ for each pair of taxa in the

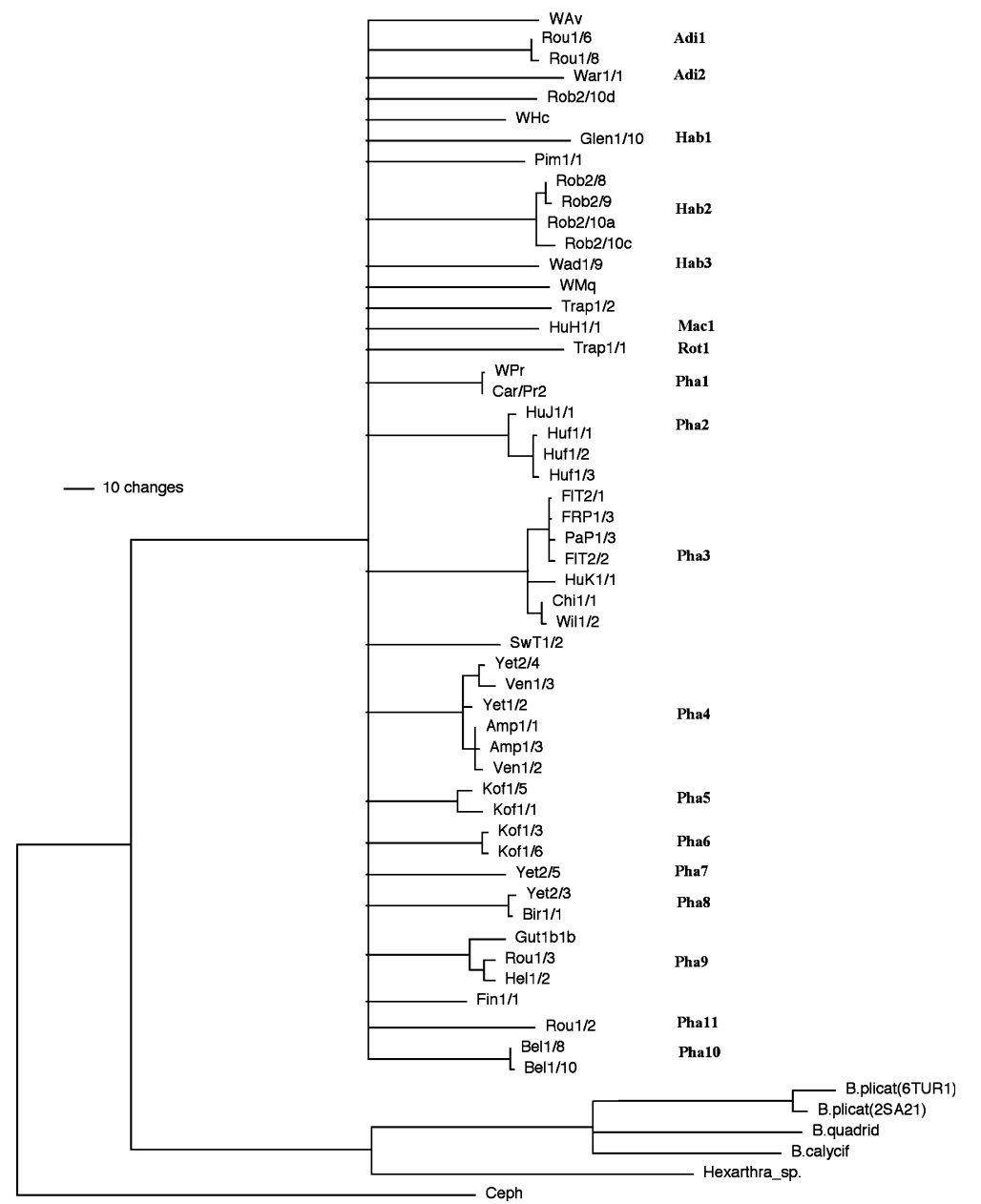

Figure 4. Phylogenetic tree of 56 rotifer clones (large dataset) plus a cephalopod, Gonatus onyx. The tree was made with the parsimony algorithm in PAUP* and rooted with the cephalopod as outgroup. All clades are supported by $\geq 70 \%$ of 1000 heuristic bootstraps. Clades are named on the right; in some cases only one member of a clade is represented in this dataset. 


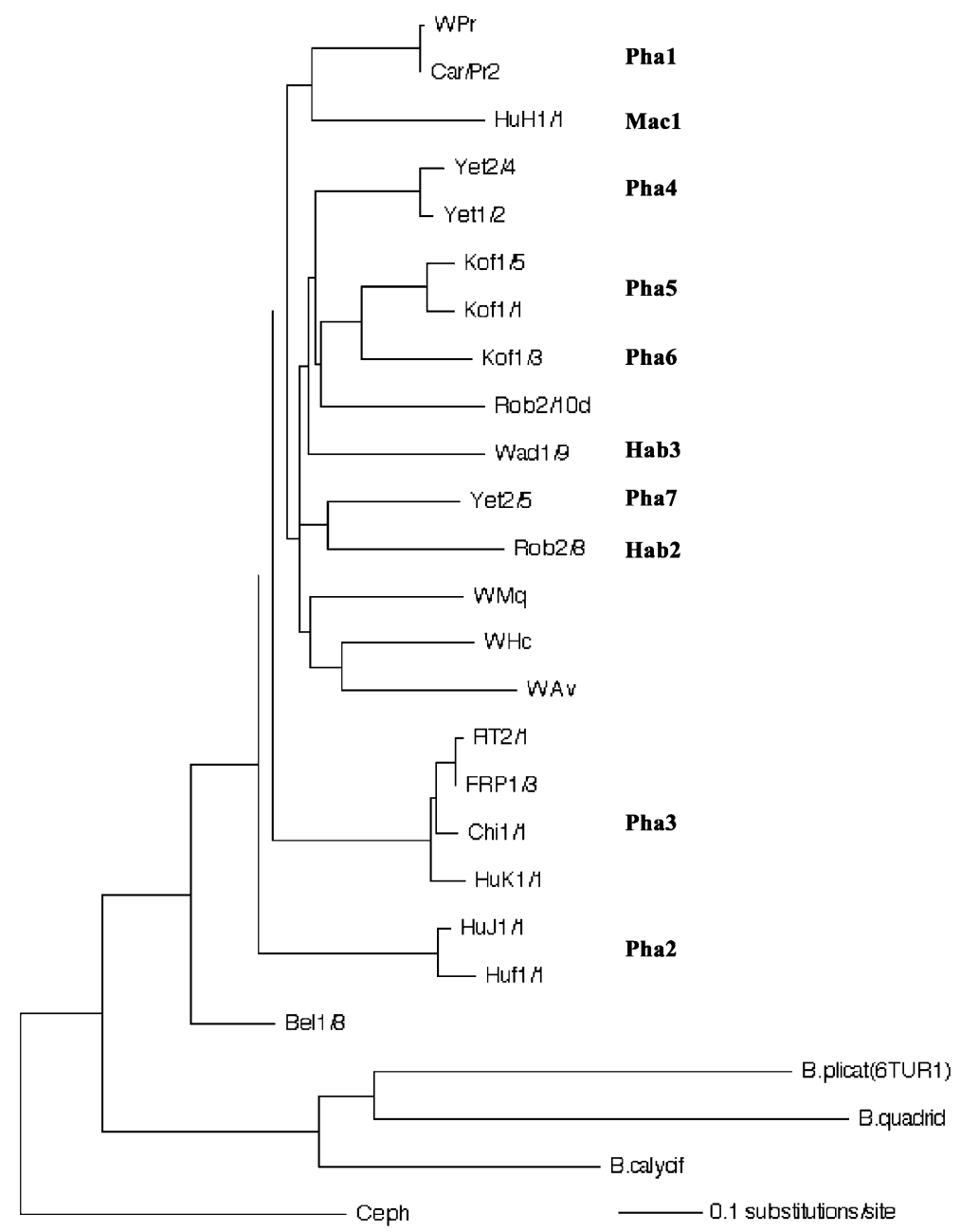

Figure 5. Phylogenetic tree of 25 rotifer clones (small dataset) plus a cephalopod, Gonatus onyx. The tree was made with the neighborjoining algorithm in PAUP*, using the Jukes-Cantor model, and rooted with the cephalopod as outgroup. All clades are supported by $\geq 70 \%$ of 1000 bootstraps in a separate analysis. Clades are named on the right; in some cases only one member of a clade is represented in this dataset.

dataset. We did the same analysis with the small dataset to look for effects of taxon sampling. Because some substitutions in the first and second codon positions are synonymous and some substitutions in the third codon position are not, we used two other methods to estimate $K_{\mathrm{a}}$ and $K_{\mathrm{s}}$. We used the method of Nei \& Gojobori (1986), implemented in PAML (Yang, 2000), to estimate $K_{\mathrm{a}}$ and $K_{\mathrm{s}}$ for each pair of bdelloids and monogononts; then we calculated the pairwise values of $\mathrm{K}_{\mathrm{a}} / K_{\mathrm{s}}$. Finally, we used the maximum likelihood model of Goldman \& Yang (1994), also implemented in PAML, to estimate $K_{\mathrm{a}} / K_{\mathrm{s}}$ on each branch in the phylogenetic tree of Figure 5. These methods were applied only to the small dataset because they are computationally intensive; the results are summarized in Table 3. All of our estimates of the mean $K_{\mathrm{a}} / K_{\mathrm{s}}$ for the bdelloids are well below 1 (a value of 1 indicates complete relaxation of selection), and most are less than 0.1 , indicating strong selection on the $\operatorname{cox} 1$ gene. It is important to note that selection was strong not only on average but also in most of the individual branches of the bdelloid phylogenetic tree.

The Jukes-Cantor and Goldman and Yang models do not allow variation in substitution rates among sites. This is problematic a priori, because 
Table 3. Effectiveness of selection on bdelloids and monogononts, indicated by various estimates of $K_{\mathrm{a}} / K_{\mathrm{s}}$ for the coxl gene

\begin{tabular}{lllllllll}
\hline Dataset & Estimate & Model & Organisms & Mean & Minimum & Maximum & Std. Dev. & Mann-Whitney probability \\
\hline Large & Pairwise $K_{12} / K_{3}$ & \multirow{2}{*}{ JC } & Bdelloids & 0.0624 & 0 & 1 & 0.0495 & $<0.02$ \\
& & & Monogononts & 0.1006 & 0.0488 & 0.1617 & 0.0464 & \\
\multirow{2}{*}{ Small } & Pairwise $K_{12} / K_{3}$ & \multirow{2}{*}{ JC } & Bdelloids & 0.0732 & 0.0037 & 0.178 & 0.0413 & 0.36 \\
& & & Monogononts & 0.0802 & 0.048 & 0.1434 & 0.0547 & \\
\multirow{2}{*}{ Small } & Pairwise $K_{12} / K_{3}$ & \multirow{2}{*}{ NG } & Bdelloids & 0.1703 & 0.0172 & 0.3331 & 0.1446 & $<0.01$ \\
& & & Monogononts & 0.0341 & 0 & 0.1018 & 0.0243 & \\
\multirow{2}{*}{ Small } & \multirow{2}{*}{$K_{\mathrm{a}} / K_{\mathrm{s}}$ on branches } & \multirow{2}{*}{ ML } & Bdelloids & 0.0047 & 0.0006 & 0.02 & 0.0059 & 0.2 \\
& & & Monogononts & 0.004 & 0.0018 & 0.0067 & 0.0025 & \\
\hline
\end{tabular}

Evolutionary models used to correct for multiple hits are those of Jukes and Cantor (JC), Nei and Gojobori (NG), and the maximum likelihood model of Goldman and Yang (ML). The Mann-Whitney probability is the probability that the monogononts and bdelloids have the same mean, determined with the Mann-Whitney $U$ test.

we expect many sites at the first and second codon position and some amino acids to be invariant or nearly so when selection is strong. This would lead to an underestimate of $K_{\mathrm{a}} / K_{\mathrm{s}}$. Therefore, we also applied two of the variable sites models implemented in PAML. These models allow $K_{\mathrm{a}} / K_{\mathrm{s}}$ to vary among sites (codons) in each branch, but the ratio $K_{\mathrm{a}} / K_{\mathrm{s}}$ is constrained to be the same on all branches. Because the great majority of the branches are among the bdelloids, the overall $K_{\mathrm{a}} / K_{\mathrm{s}}$ estimate is probably close to what would be obtained with bdelloids alone. The model of Yang (1994) with three discrete classes of substitutions (model M3 in PAML) estimated $K_{\mathrm{a}} / K_{\mathrm{s}}$ as 0.0329 in the bdelloids, similar to the estimates in Table 3. In contrast, the Nielsen \& Yang (1998) model with a continuous beta distribution (model M7 in PAML) gave $K_{\mathrm{a}} / K_{\mathrm{s}}=0.2168$, slightly higher than the NG value.

We used several different methods to estimate $K_{\mathrm{a}} / K_{\mathrm{s}}$ because there is some disagreement about which method is the most accurate; the differences among these estimates reflect the methodological differences. The important point is that all methods show strong selection.

There is some evidence that the synonymous substitutions on the deep branches are saturated in our data set (David Mark Welch, Matthew Meselson, and Michael Cummings, personal communication). If so, we have underestimated $K_{\mathrm{s}}$ and overestimated $K_{\mathrm{a}} / K_{\mathrm{s}}$ and selection on coxl is even stronger than these numbers show.

We compared these $K_{\mathrm{a}} / K_{\mathrm{s}}$ values for bdelloids to those of sexual organisms. For the small sample of monogononts in our analyses, $K_{\mathrm{a}} / K_{\mathrm{s}}$ was not significantly different in two methods, was significantly higher in the bdelloids in one comparison, and was significantly lower in one (Table 3). Lynch \& Blanchard (1998) calculated the pairwise $K_{\mathrm{a}} / K_{\mathrm{s}}$ for a large sample of protein-coding genes from a broad spectrum of invertebrates; the mean was 0.13 , higher than that for either the bdelloids or monogononts in our sample. Giribet et al. (2001) obtained coxl sequences from a large sample of arthropod taxa. We calculated pairwise values of $K_{12} / K_{3}$ with the Jukes-Cantor model for $651 \mathrm{bp}$ of their sequences from 23 arthropods, obtaining a mean value of 0.15 , again higher than in our rotifers. We calculated the mean pairwise $K_{12} / K_{3}=0.089$, again with the Jukes-Cantor model, for 957-bp coxl sequences from 75 leaf beetles (Funk, 1999). Most or all of the organisms in these datasets are obligately sexual. These comparisons lead us to conclude that the loss of sexual reproduction in the bdelloids resulted in little or no reduction in the effectiveness of selection on the coxl gene.

\section{Discussion}

Bdelloids have undergone substantial cladogenesis

Our data show that the bdelloid rotifers have undergone substantial cladogenesis. This is the first demonstration of substantial cladogenesis in an obligately asexual lineage using sequence data. Of these clades, 21 show two important characteristics of species: modest sequence diversity, characteristic of species in sexual animals, and 
reciprocal monophyly. The latter is a key feature of the cladistic and phylogenetic concepts. It also shows that the clades, and the natural populations they represent, have been evolving independently of each other for a long time, as required by the evolutionary species concept. Each is thus an independent arena for the basic evolutionary processes of mutation, drift, and selection. This is the basis of the cohesion species concept.

\section{Bdelloid clades are adapted to different niches}

At least some of the clades differ in morphology and behavior, showing that they are adapted to different niches. In further support of this, we demonstrated differences in food utilization between two clones, and in temperature tolerance between clones of two clades. We also found no evidence for isolation by distance in our bdelloids. If the different clades are not isolated from each other by distance, then they must be adapted to different niches in order to be evolving independently.

\section{Bdelloids have undergone substantial speciation}

We conclude that the clades we identified can be considered different species by most of the species definitions that are applicable to asexual organisms. If this is correct, then the bdelloid rotifers have undergone substantial speciation in the absence of sexual reproduction. This is the first demonstration of substantial speciation in an asexual lineage, based on phylogenetic analysis of DNA sequences. The extent to which these species correspond to the species already identified on the basis of morphology remains to be seen. We also note that our data support the suggestion of Hebert et al. (2003) that sequences of the coxl gene can be used as 'DNA barcodes' for the identification of species.

\section{No detectable decrease in the effectiveness of natural selection on bdelloid genes}

We failed to detect a greater accumulation of detrimental mutations in bdelloids, relative to monogononts and other sexual invertebrates, in the mitochondrial coxl gene. Mark Welch \& Meselson (2001) previously showed that the nuclear hsp82 gene of clones WPr, WMq, WAv, and WHc are under strong selection in both bdelloids and monogononts. There are several possible explanations:

1. The genes used in these studies may be too strongly selected to be useful for this purpose. The ratio $K_{\mathrm{a}} / K_{\mathrm{s}}$ depends on the fixation probability of a new mutation. This in turn is a function of $N_{\mathrm{e}} s$, where $N_{\mathrm{e}}$ is the effective population size and $s$ is the selection coefficient of the mutation. The reduced effectiveness of selection in asexuals can be viewed as a reduction in $N_{\mathrm{e}}$, but when $s$ is very large, it takes a very large reduction in $N_{\mathrm{e}}$ to produce a detectable change in $N_{\mathrm{e}} s$ and the fixation probability (theoretical results not shown). In other words, when selection is sufficiently intense, genetic drift is not very important in either sexual or asexual species. It is possible that an analysis of other genes that are subject to less stringent selection in monogononts, and hence more sensitive to a reduction in selection intensity, would show that some have accumulated dangerously large loads of detrimental mutations. Recently, David Mark Welch, Matthew Meselson, and Michael Cummings (personal communication) estimated $K_{\mathrm{a}} / K_{\mathrm{s}}=0.05$ for our combined sequences of coxl and another mitochondrial gene, $c o b$, for four bdelloid clones (WPr, $\mathrm{WMq}, \mathrm{WAv}$, and $\mathrm{WHc}$ ). We also found a low value of $K_{\mathrm{a}} / K_{\mathrm{s}}$ for $c o b$ alone in a larger sample of bdelloids (data not shown).

2. The effective population size of rotifers may be so large that the decrease due to loss of sexual reproduction isn't readily detectable. This is unlikely, because the independently evolving clades show sequence diversity similar to that of sexual organisms. This sequence diversity is a function of $N_{\mathrm{e}} u$ where $u$ is the mutation rate. If $N_{\mathrm{e}}$ is unusually large in bdelloids, then the mutation rate must be unusually small. Even if bdelloids may very large census population sizes, we suspect that the number of offspring per female is extremely variable due to their opportunistic life style. If so, their variance effective population size would still be modest.

3. The phenotypic effects of new mutations may have changed in bdelloids. As discussed above, the effect of the loss of sex on the ratio $K_{\mathrm{a}} / K_{\mathrm{s}}$ 
depends on the product $N_{\mathrm{e}} s$. The reduction in $N_{\mathrm{e}}$ due to the loss of sex could be compensated by a decrease in the selection coefficient $s$ for nonsynonymous substitutions (i.e., they became less detrimental), or to an increased effectiveness of selection for synonymous substitutions (selection for codon bias increased). Another possibility is that detrimental mutations may be more strongly detrimental in bdelloids than in otherwisesimilar sexual lineages. Strongly detrimental mutations are rarely fixed by random drift in asexual or sexual lineages and are unlikely to contribute to $K_{\mathrm{a}} / K_{\mathrm{s}}$ (Gabriel et al., 1993). A change in fitness effects of new mutations is plausible because the fitness of a new mutation is influenced by the background genotype and can be modified by selection (Rutherford, 2000; Hartman et al., 2001).

4. There may be an ascertainment bias. We are seeing only the lucky survivors who survived because they haven't accumulated many detrimental mutations by chance. We will use our larger sample of bdelloids to estimate the strength of selection along branches at varying distances from the tip of the tree. The newest lineages have had less time in which to become extinct and should not be subject to this bias.

We do not know how large a load of detrimental mutations is needed to push a population of bdelloids over the brink into extinction, but they do not appear to be any closer to extinction than their sexual relatives.

We said at the outset that two basic problems of biology intersect in asexual organisms like the bdelloids: the evolutionary advantage of sex, and the nature of species. Theory predicts that natural selection should be weaker in asexual organisms, compared to sexual organisms. Consequently, asexuals should be less able to retain and fix the mutations needed adapt to different niches, and have a lower rate of speciation. Theory also predicts that asexual organisms should accumulate more detrimental mutations than sexual organisms, leading to a higher rate of extinction of species. The net effect would be a lower rate of speciation in asexuals than in sexuals, all else being equal. Our results show that the bdelloid rotifers can speciate, possibly because all else is not equal.
Future studies will look for features of the bdelloids that might compensate for the loss of sex.

\section{Acknowledgements}

Many people provided helpful comments and constructive criticism, including Timothy Barraclough, Douglas Futuyma, Africa Gómez, David Hillis, Charles King, Wayne Maddison, Brian McGill, Claudia Ricci, David Mark Welch, Robert Wallace, Elizabeth Walsh, and an anonymous reviewer. Michael Dellinger, Marlea Gemmel, Dee Haefner, Catarina Kazcurkin, Julia Perry, and Michael Nodine assisted in the lab. Our research was supported by startup funds provided to CWB by the University of Arizona and a Grant-in-Aid to LH from the Society of Sigma Xi; salary from the Undergraduate Biology Research Program for CW and EH; a MacNair Scholarship for $\mathrm{LH}$; and a research associateship from the Genetics Program for HM.

\section{References}

Avise, J. C., 1994. Molecular Markers, Natural History and Evolution. Chapman \& Hall, Inc., New York.

Avise, J. C. \& R. M. Ball Jr., 1990. Principles of genealogical concordance in species concepts and biological taxonomy. In Futuyama, D. \& J. Antonovics (eds), Oxford Surveys in Evolutionary Biology. Oxford University Press, Oxford: 4567.

Barraclough, T. G., C. W. Birky, Jr. \& A. Burt, 2003. Diversification in sexual and asexual organisms. Evolution 57: 2166-2172.

Barton, N. H. \& B. Charlesworth, 1998. Why sex and recombination? Science 281: 1987-1990.

Bell, G., 1982. The Masterpiece of Nature. Croom Helm, London.

Birky, C. W. Jr., 1996. Uniparental inheritance of mitochondrial and chloroplast genes: mechanisms and evolution. Proceedings of the National Academy of Sciences of the United States of America 92: 11331-11338.

Birky, C. W. Jr. \& J. B. Walsh, 1988. Effects of linkage on rates of molecular evolution. Proceedings of the National Academy of Sciences of the United States of America 85: 6414 6418.

Birky, C. W., T. Maruyama \& P. Fuerst, 1983. An approach to population and evolutionary genetic theory for genes in mitochondria and chloroplasts and some results. Genetics 103: 513-527.

Bohonak, A. J., 2002. IBD (Isolation By Distance): a program for analysis of isolation by distance. Journal of Heredity 93: $153-154$ 
Cáceres, C. E. \& D. A. Soluk, 2002. Blowing in the wind: a field test of overland dispersal and colonization by aquatic invertebrates. Oecologia 131: 402-408.

Derry, A. M., P. D. N. Hebert \& E. E. Prepas, 2003. Evolution of rotifers in saline and subsaline lakes: a molecular phylogenetic approach. Limnology and Oceanography 48: 675-685.

Donner, J., 1965. Ordnung Bdelloidea. Akademie Verlag, Berlin, $297 \mathrm{pp}$.

Funk, D. J., 1999. Molecular systematics of cytochrome oxidase I and $16 \mathrm{~S}$ from Neochlamisus leaf beetles and the importance of sampling. Molecular Biology and Evolution 16: $67-82$.

Gabriel, W., M. Lynch \& R. Bürger, 1993. Muller's ratchet and mutational meltdown. Evolution 47: 1744-1757.

Gilbert, D. G., 1992. SeqApp, a biological sequence editor and analysis program for Macintosh computers. Published electronically on the Internet, available via gopher or anonymous ftp to ftp.biol.indiana.edu.

Giribet, G., G. D. Edgecombe \& W. C. Wheeler, 2001. Arthropod phylogeny based on eight molecular loci and morphology. Nature 413: 157-161.

Goldman, N. \& Z. Yang, 1994. A codon-based model of nucleotide substitution for protein-coding DNA sequences. Molecular Biology and Evolution 11: 725-736.

Gómez, A., 2005. Molecular ecology of rotifers: from population differentiation to speciation. Hydrobiologia 546: 83-99.

Gómez A., G. R. Carvalho \& D. H. Lunt, 2000. Phylogeography and regional endemism of a passively dispersing zooplankter: mitochondrial DNA variation in rotifer resting egg banks. Proceedings of the Royal Society of London. Series B, Biological Sciences 267: 2189-2197.

Hartman, J. L. I., B. Garvik \& L. Hartwell, 2001. Principles for the buffering of genetic variation. Science 291: 1001-1004.

Hebert, P. D. N., A. Cywinska, S. L. Ball \& J. R. deWaard, 2003. Biological identification through DNA barcodes. Proceedings of the Royal Society of London. Series B, Biological Sciences 270: 313-321.

Hill, W. G. \& A. Robertson, 1966. The effect of linkage on limits to artificial selection. Genetical Research 38: 226-231.

Hoeh, W., M. Black, R. Gustafson, A. Bogan, R. Lutz \& R. Vrijenhoek, 1998. Testing alternative hypotheses of Neotrigonia (Bivalvia:Trigonioida) relationships using cytochrome C oxidase subunit I DNA sequences. Malacalogia 40: 267-278.

Holman, E. W., 1987. Recognizability of sexual and asexual species of rotifers. Systematic Zoology 36: 381-386.

Hudson, R. R. \& J. A. Coyne, 2002. Mathematical consequences of the genealogical species concept. Evolution 56: $1557-1565$.

Kondrashov, A. S., 1993. Classification of hypotheses on the advantage of amphimixis. Journal of Heredity 84: 372-387.
Lynch, M. \& J. L. Blanchard, 1998. Deleterious mutation accumulation in organelle genomes. Genetica 102/103: 29-39.

Mark Welch, D. B. \& M. Meselson, 2001. Rates of nucleotide substitution in sexual and anciently asexual rotifers. Proceedings of the National Academy of Sciences of the United States of America 98: 6720-6724.

Maruyama, T. \& C. W. Birky Jr., 1991. Effects of periodic selection on gene diversity in organelle genomes and other systems without recombination. Genetics 127: 449-451.

Moriyama, E. N. \& J. R. Powell, 1996. Intraspecific nuclear DNA variation in Drosophila. Molecular Biology and Evolution 13: 261-277.

Nei, M. \& T. Gojobori, 1986. Simple methods for estimating the numbers of synonymous and nonsynonymous nucleotide substitutions. Molecular Biology and Evolution 3: 418-426.

Nielsen, R. \& Z. Yang, 1998. Likelihood models for detecting positively selected amino acid sites and applications to the HIV-1 envelope gene. Genetics 148: 929-936.

Posada, D. \& K. A. Crandall, 1998. MODELTEST: testing the model of DNA substitution. Bioinformatics 14: 817-818.

Ricci, C., 1984. Culturing of some bdelloid rotifers. Hydrobiologia 112: 45-51.

Ricci, C., 1991. Comparison of five strains of a parthenogenetic species, Macrotrachela quadricornifera (Rotifera, Bdelloidea). Hydrobiologia 211: 147-155.

Ronneberger, D., 1998. Uptake of latex beads as size-model for food of planktonic rotifers. Hydrobiologia 387/388: 445449.

Rosenberg, N. A., 2003. The shapes of neutral gene genealogies in two species: probabilities of monophyly, paraphyly, and polyphyly in a coalescent model. Evolution 57: 1465-1477.

Rutherford, S. L., 2000. From genotype to phenotype: buffering mechanisms and the storage of genetic information. BioEssays 22: 1095-1105.

Segers, H., 2002. The nomenclature of the Rotifera: annotated checklist of valid family- and genus-group names. Journal of Natural History 36: 631-640.

Swofford, D. L., 1998. PAUP*: Phylogenetic Analysis Using Parsimony (*and Other Methods). Version 4. Sinauer Associates, Sunderland, Massachusetts.

Vadstein, O., G. Oie \& Y. Olsen, 1993. Particle size dependent feeding by the rotifer Brachionus plicatilis. Hydrobiologia 255/256: 261-267.

Yang, Z., 1994. Maximum likelihood estimation from DNA sequences with variable rates over sites: approximate methods. Journal of Molecular Evolution 39: 306-314.

Yang, Z., 2000. Phylogenetic Analysis by Maximum Likelihood (PAML). London, England, University College London. 